\title{
Neuroleptic Malignant Syndrome Associated with Rhabdomyolysis Induced by Antipsychotic Agents: A Rare Occurrence
}

\author{
Ankit R. Mistry, Sapna D. Gupta, and Supriya D. Malhotra
}

\section{ABSTRACT}

\begin{abstract}
Neuroleptic Malignant Syndrome (NMS) is a medical emergency of infrequent presentation in Emergency department, which is associated with the use of psychotropic agents, classical and atypical antipsychotics. We report a case involving a 56-year-old male patient diagnosed with schizophrenia and depression for 30 years, who had been receiving Amisulpride, Trifluoperazine, Clozapine, and Amitryptiline as part of his treatment. This patient presented with symptoms of NMS with fever, muscle rigidity, altered mental state, elevated CPK, Urea, and S. Creatinine levels. NMS may be responsible for serious rhabdomyolysis, acute respiratory distress syndrome, and disseminated intravascular coagulation. We hypothesize the occurrence of acute renal failure precipitated by NMS. His treatment included the withdrawal of all psychotropic agents, Bromocriptine, and other supportive measures.
\end{abstract}

Keywords: Elevated CPK, Neuroleptic Malignant Syndrome (NMS), Rhabdomyolysis, Trifluoperazine.

\section{INTRODUCTION}

Neuroleptic Malignant Syndrome (NMS) is an uncommon but potentially fatal idiosyncratic reaction to neuroleptics, characterized by signs of autonomic instability (hyperthermia and labile pulse, blood pressure, and respiration rate), stupor, the elevation of creatine kinase in serum, and sometimes myoglobinemia with potential nephrotoxicity [1]. NMS is a rare but fatal Extrapyramidal side effect (EPS). Although potent neuroleptics (e.g., Haloperidol, Trifluoperazine, and Fluphenazine) are more frequently associated with NMS and rare with newer antipsychotic drugs [2], [3]. Amisulpride and Clozapine are atypical antipsychotic agents used in Schizophrenia, manic depressive illness, and atypical depression [4]. Rhabdomyolysis is a severe and potentially life-threatening medical emergency involving the destruction of skeletal muscle, due to a wide range of etiologies that ultimately converge in a common pathway leading to irreversible muscle breakdown [5]. Whilst in some cases rhabdomyolysis may be exclusive because of external triggers (e.g., trauma, local ischemia, exertional exercise) and sometimes it may be due to malignant hyperthermia, neuroleptic malignant syndrome (NMS), and serotonin syndrome. In this case report, we present a patient with NMS on treatment with Amisulpride, Trifluoperazine, and Clozapine who developed acute renal failure due to rhabdomyolysis.
Published Online: August 30, 2021

ISSN: $2736-5476$

DOI10.24018/ejclinicmed.2021.2.4.117

A. R. Mistry

Smt. NHL Municipal Medical College, Ahmedabad, Gujarat, India.

(e-mail: ankit.mistry93.am@gmail.com)

S. D. Gupta

Smt. NHL Municipal Medical College,

Ahmedabad, Gujarat, India.

(e-mail: sapna_gupta76@yahoo.com)

S. D. Malhotra*

Smt. NHL Municipal Medical College,

Ahmedabad, Gujarat, India.

(e-mail: supriyadmalhotra@gmail.com)

*Corresponding Author

\section{OBSERVATIONS}

\section{A. Case Details}

A 56-year-old male patient history of schizophrenia and depression for 30 years and also a chronic smoker for 20 years presented to a tertiary care hospital. According to the informant, the patient was asymptomatic before 15 days, and then started having complaints of anorexia, high-grade fever, lack of sleep, altered sensorium, and restlessness. Prior to admission to our hospital, the patient was admitted to a private hospital for the past 12 days. The patient was taking psychiatric treatment since his diagnosis and was currently on Tab. Clozapine $500 \mathrm{mg} /$ day, Tab Amisulpride $300 \mathrm{mg} /$ day, Tab Trifluoperazine $10 \mathrm{mg} /$ day and Tab Amitriptyline $37.5 \mathrm{mg} / \mathrm{day}$ at the time of admission.

On admission, general physical examination showed a temperature was $102^{\circ} \mathrm{F}$, HR 76 beat $/ \mathrm{min}, \mathrm{BP}$ of $128 / 80 \mathrm{mmHg}$, and RR of $18 / \mathrm{min}$. The neurological examination showed the patient was conscious, partially cooperative, and disoriented to time, place, and person. The pupil was constricted bilateral, muscle tone- mild rigidity in all 4 limbs, the plantar reflex was normal. Psychiatric reference was done which showed relevant incoherent speech with a minimal response with a decrease rate and volume and increased psychomotor agitation (PMA). Examination of the chest, cardiovascular system, and abdomen were unremarkable. 
His investigations on the day of admission were as follows: $\mathrm{Hb} 7.9$ g/dL (12-18), WBC: 17540 cells/cumm (520012400), platelets: $\mathbf{6 , 1 3 , 0 0 0}$ cells/cumm $(1,30,000-4,00,000)$, Creatinine: $8.66 \mathbf{~ m g} / \mathbf{d L}(0.7-1.3)$, Urea: 182.8 mg/dL (1545), SGPT: 82 U/L(10-49), SGOT: 220 U/L(0-34), ALP: 76 U/L(45-129), Albumin: 2.8 g/dL (3.2-4.8), CRP: 43.13 mg/L (<5.0), CPK: 60000 U/L(22-198), and PTH: 300.1 pg/dL (10-65). Urine routine examination showed presence of Protein $(++)$, Ketone $(+++)$, Urobillinogen $(++)$ and albumin/ Creatinine ratio was $1908.43 \mathrm{mg} / \mathrm{g}$. he was diagnosed with Neuroleptic Malignant Syndrome (NMS) probably due to antipsychotic therapy he was receiving with associated rhadbomyolysis with acute kidney injury.

All psychotropic medications were withdrawn. Tab Bromocriptine $2.5 \mathrm{mg}$ TDS, Tab Donepezil $10 \mathrm{mg}$ BD, Tab. Amantadine $100 \mathrm{mg}$ BD, Tab. Glycopyrrolate $1 \mathrm{mg}$ TDS, Tab Lorazepam $2 \mathrm{mg}$ SOS were prescribed. Inj. Meropenem 500 mg TDS, Inj. Clindamycin 600 mg TDS, Inj Albumin, and were given as supplementary treatment. On day 2, laboratory investigation was repeated and CPK levels were low as compared to the time of admission (Fig. 1). Patient underwent hemodialysis on every alternate day. Patient $\mathrm{Sp}_{2}$ was decreased and then he was stabilized with oxygen therapy. S.Creatinine and Urea levels remained high and fluctuating (Fig. 2).

Other laboratory findings were also abnormal like CBC (Hb: 8.1 g/dL, WBC: 18940 cells/cumm, platelets: 6,49,000 cells/cumm), LDH (542 U/L), SGPT (75 U/L), S. Creatinine$7.66 \mathrm{mg} / \mathrm{dL}$, Urea- $163.9 \mathrm{mg} / \mathrm{dL}$ and Procalcitonin- 0.19 (0$0.1 \mathrm{ng} / \mathrm{dL})$. Further evaluation for other causes of rhabdomyolysis including trauma, history of alcohol and infections was ruled out.

On $5^{\text {th }}$ day of admission, the patient showed clinical improvement. Neurological examination revealed, he was conscious but confused, bilateral pinpoint pupil, normal tone of muscle in all four limbs, plantar reflex bilateral extensor, and reflexes present but depressed (biceps +1 , tricepes +1 , knee +1 , ankle +1$)$. General condition showed that temperature was normal, HR 64/min, BP 150/92 mmHg, and RR $18 / \mathrm{min}$. His $\mathrm{SpO}_{2}$ was $98 \%$ on NIV with PSV 10 PEEP 6 $\mathrm{FiO}_{2} 80 \%$. Patient's Urea and S. Creatinine level began to decrease after dialysis was done but values are not within the normal limit.

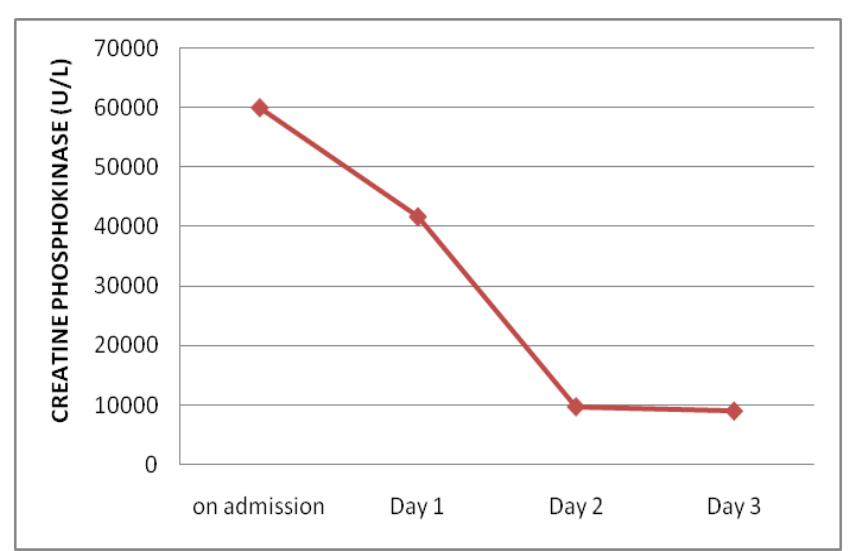

Fig. 1. Trend of CPK value in blood prior and during hospitalization.

\section{S. creatinine and Urea level}

S. Creatinine $(\mathrm{mg} / \mathrm{dL}) \quad$ Urea $(\mathrm{mg} / \mathrm{dL})$

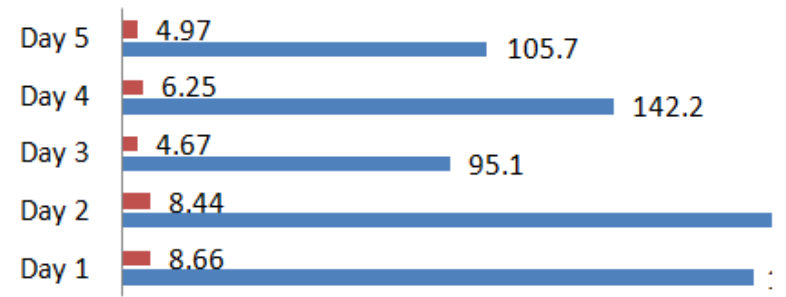

Fig. 2. S. creatinine and Urea level during hospitalization.

The patient's relatives opted for discharge against medical advice (DAMA) due to chronic diseases and anticipated prolonged hospital stay. The patient was discharged with medication consisting of Tab Bromocriptine $2.5 \mathrm{mg}$ TDS, Tab Amantadine $100 \mathrm{mg}$ BD, Tab Glycopyrrolate $1 \mathrm{mg}$ TDS and other supportive medications. He was referred to psychiatry for treatment of his mental condition. This case was reported to the closest ADR monitoring center under Pvpi via Vigiflow with unique Id: IN-IPC-300553650.

\section{DISCUSSION}

The term known as NMS was first reported in 1960 by French psychiatrists [6]. The incidence of NMS is $0.02-3 \%$ in patients taking antipsychotic drugs [4]. In the present study, we aim to review the clinical features of patients with NMS which is associated with rhabdomyolysis. This syndrome is well described in a plethora of literature, with one of its main key symptoms being excessive hyperthermia.

The pathogenesis behind the cause of NMS is only speculative and has not yet been clearly defined [7]. Our patient presented with a life-threatening condition manifesting as hyperthermia, muscle rigidity, changes in mental state, blood pressure oscillations, and increase CPK. Most of the other possible causes of hyperthermia were ruled out. Our case documents objectively the occurrence of NMS because of the use of antipsychotic agents. He had schizophrenia and depression for 30 years and was treated with Amisulpride, Trifluoperazine, Amitriptyline, and Clozapine at the time of admission.

Amitriptyline is a tricyclic antidepressant and not associated with NMS. Among the antipsychotics prescribed to this patient. Trifluoperazine belongs to the class of classical antipsychotic agents and is most frequently associated with NMS as compared to atypical antipsychotics [10]. As far as Amisulpride is concerned, it is a secondgeneration antipsychotic drug that works by highly selective D2/D3 receptor antagonism. EPS have been reported with Amisulpride but NMS is rare [4]. Clozapine appears to be more selective for mesolimbic than nigrostriatal dopamine pathways. It is binded to $D_{1}$ and $D_{2}$ receptors is relatively weak, but it has high affinity for $\mathrm{D}_{4}$ receptors [9]. Association of Clozapine with NMS has been scarcely documented in the literature. Notably, Trifluoperazine, in the above-mentioned case appears to be the drug responsible for this adverse effect.

Conventionally, Dantrolene can be given intravenously for severe cases of muscle rigidity, but the case in question here 
received Bromocriptine. Treatment with this drug, which is a direct $\mathrm{D}_{2}$ receptor agonist, was reported to significantly shorten the time to recovery compared to supportive therapy alone. Simultaneously, in our patient renal parameters were also altered during hospitalization. Patient's CPK, urea and creatinine levels were extremely high and urine examination fulfilled diagnostic criteria for rhabdomyolysis. Rhabdomyolysis-induced acute renal failure (myoglobinuric renal failure) was first described during the London 'blitz' in World War II [8]. This observation suggests that classical antipsychotic Trifluoperazine could be the causative agent for NMS and rhabdomyolysis seen in this patient.

The commonest cause of rhabdomyolysis is non-traumatic [11]. The pathophysiology of acute renal failure associated with rhabdomyolysis is multifactorial (Table I). The use of dopamine agonists caused clinical improvement in this case. The overall mortality in NMS ranges from 11.6 to $25 \%$. To note, the concomitant presence of rhabdomyolysis and acute renal failure increases the mortality risk to nearly $50 \%$.

TABLE I: PHYSICAL AND NONPHYSICAL CAUSES OF RHABDOMYOLYSIS

\begin{tabular}{|c|c|}
\hline Conditions & Causes \\
\hline \multicolumn{2}{|l|}{ Physical Causes } \\
\hline $\begin{array}{l}\text { Trauma and } \\
\text { compression }\end{array}$ & $\begin{array}{c}\text { Crush syndrome, motor vehicle accidents, } \\
\text { prolonged immobilization }\end{array}$ \\
\hline Exertion & $\begin{array}{l}\text { Strenuous exercise, seizures, alcohol withdrawal } \\
\text { syndrome }\end{array}$ \\
\hline Muscle hypoxia & $\begin{array}{c}\text { Major artery occlusion (embolus, thrombus), } \\
\text { vessel clamping during surgery }\end{array}$ \\
\hline $\begin{array}{l}\text { Body temperature } \\
\text { changes }\end{array}$ & $\begin{array}{l}\text { Malignant hyperthermia, neuroleptic malignant } \\
\text { syndrome, heat stroke, hypothermia }\end{array}$ \\
\hline \multicolumn{2}{|l|}{$\begin{array}{l}\text { Nonphysical } \\
\text { Causes }\end{array}$} \\
\hline Drugs and toxins & $\begin{array}{l}\text { Psychiatric Agents, Abused Substances, } \\
\text { Antihistamines, Statins, Antilipid Agents }\end{array}$ \\
\hline Infections & $\begin{array}{c}\text { Influenza A and B, coxsackie virus, Epstein- } \\
\text { Barr virus, primary HIV, herpes virus, } \\
\text { Salmonella, Streptococcus pyogenes, }\end{array}$ \\
\hline Electrolyte & Staphylococcus aureus, Clostridium, sepsis \\
\hline imbalances & Hypokalemia, hypophosphatemia, hypocalcemia \\
\hline Endocrine disorders & $\begin{array}{l}\text { Hyperaldosteronism, hypothyroidism, diabetic } \\
\text { ketoacidosis }\end{array}$ \\
\hline
\end{tabular}

\section{CONCLUSION}

NMS is an uncommon and lethal neurological disorder, attributed to the administration of typical antipsychotics and less commonly to the atypical antipsychotics, like Clozapine and Amisulpride. NMS could be diagnosed with close attention to clinical symptoms, a detailed physical and neurological examination, and high suspicion of culprit medications.

\section{REFERENCES}

[1] P. D. Rogers, D. J. Krysan, “Antifungal Agents. In: Brunton LB, Lazo JS, Parker KL, eds. Goodman \& Gilman's The Pharmacological Basis of Therapeutics. 13th ed. New York, NY: McGraw-Hill; 2018.

[2] J. R. Carbone, "The neuroleptic malignant and serotonin syndromes," Emergency Medicine Clinics of North America, 18:2, pp. 317-325, 2000 .

[3] S. N. Caroff, S. C. Mann, "Neuroleptic malignant syndrome," Psychopharmacology Bulletin, 24:1, pp. 25-29, 1988.

[4] M. C. Tu, C. C. Hsiao, "Amisulpride and neuroleptic malignant syndrome.” Chang Gung Med J, 34:5, pp. 536-40, 2011.

[5] N. Kruijt, L. R. van den Bersselaar, J. Wijma, W. Verbeeck, M. J. Coenen, J. Neville, M. Snoeck, E. J. Kamsteeg, H. Jungbluth, C.
Kramers, N. C. Voermans, "HyperCKemia and rhabdomyolysis in the neuroleptic malignant and serotonin syndromes: A literature review," Neuromuscular Disorders, 2020.

[6] Z. Korzets, E. Zelter, J. Bernheim, “Acute renal failure in the setting of the neuroleptic malignant syndrome," Nephrol Dial Transplant, 11:5 pp. 885-6, 1996.

[7] R. J. Gurrera, S. N. Caroff, A. Cohen et al., "An international consensus study of neuroleptic malignant syndrome diagnostic criteria using the Delphi method," The Journal of Clinical Psychiatry, 72:9, pp. 12221228, 2011.

[8] E. G. Bywaters, D. Beall, "Crush Injuries with Impairment of Renal Function," Br Med J, 22;1(4185):427-32, 1941.

[9] J. L. Karagianis, L. C. Phillips, K. P. Hogan, K. K. LeDrew, "Clozapine-associated neuroleptic malignant syndrome: two new cases and a review of the literature," Annals of Pharmacotherapy, 33(5):62330, 1999.

[10] J. R. Strawn, J. R. Keck, M. D. PE, S. N. Caroff, "Neuroleptic malignant syndrome," American Journal of Psychiatry, 164(6):870-6, 2007.

[11] P. A. Torres, J. A. Helmstetter, A. M. Kaye, A. D. Kaye, "Rhabdomyolysis: pathogenesis, diagnosis, and treatment," Ochsner J, 15(1):58-69, 2015

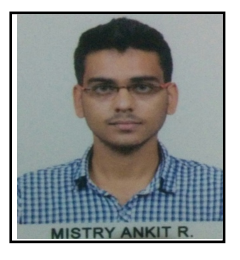

Ankit R. Mistry was born in Gujarat, India in 1993. He had done his Bachelor of Medicine and Bachelor of Surgery (M.B.B.S) degree from Government Medical College, Bhavnagar, Gujarat, India in 2016. He had 3 years' experience in hospital as a Health professional. He is now Pursuing his M.D in Pharmacology at Smt. NHL Municipal Medical College, Ahmedabad, India. 